\title{
Benzene Adsorbed on Activated Carbon: A Comprehensive Solid-State NMR Study of Interactions with the Pore Surface and Molecular Motions
}

Jordon W. Benzie, Vladimir I. Bakhmutov, ${ }^{*}$ Janet Blümel*

Department of Chemistry, Texas A\&M University, College Station, TX 77843, United States

keywords: Adsorbed benzene, paramagnetic activated carbon, chemical exchange, line shape, quadrupolar interactions, NMR relaxation

\section{Supporting Information}

This supporting information contains information about instrumentation and materials used, as well as Figures S1-S7 and Table S1.

\section{Instrumentation and Materials}

Materials. Activated carbon (AC, DARCO KB-G) was purchased from Sigma-Aldrich and used without further treatment. It has a specific surface area of $1700 \mathrm{~m}^{2} / \mathrm{g}$ and pore volumes for micro-, meso- and macropores of $0.28,0.3$, and $0.4 \mathrm{~mL} / \mathrm{g}$, respectively.

A sample of AC was immersed in liquid benzene- $d_{6}$ (Sigma-Aldrich) for 30 minutes and was then placed into a drying oven at $150^{\circ} \mathrm{C}$ for 30 minutes. The resulting dry, black powder gained $620 \mathrm{mg}$ of weight per $\mathrm{g}$ of $\mathbf{A C}$ and is designated $\mathbf{A C}-\mathbf{C}_{6} \mathbf{D}_{6}-\mathbf{6 2 0}$. Then, a sample of $\mathbf{A C}-\mathbf{C}_{6} \mathbf{D}_{6}-\mathbf{6 2 0}$ was placed into a drying oven at $150{ }^{\circ} \mathrm{C}$ for an additional 30 -minute heating period, which resulted in a weight gain of $370 \mathrm{mg}$ with respect to $1 \mathrm{~g}$ of the original AC. This material is labelled AC-C $\mathbf{C}_{\mathbf{6}} \mathbf{D}_{\mathbf{6}}-\mathbf{3 7 0}$. In order to adsorb cyclohexane- $d_{12}$ (Sigma-Aldrich), a sample of AC was immersed in liquid cyclohexane, then placed into a drying oven $\left(150^{\circ} \mathrm{C}\right)$ and heated for 45 minutes $\left(\mathbf{A C}-\mathbf{C}_{\mathbf{6}} \mathbf{D}_{\mathbf{1 2}} \mathbf{- 5 5}\right)$.

EPR Spectroscopy. The EPR spectrum of AC was recorded with a Bruker ELEXSYS II E 500 spectrometer operating at $9.75 \mathrm{GHz}$ (X-band) and using the Xepr software. Since the aim of the EPR experiment was the observation of paramagnetic species, it has been performed only at room temperature.

NMR Measurements. All NMR experiments were carried out with a Bruker Avance-400 solidstate NMR spectrometer (400 MHz for ${ }^{1} \mathrm{H}$ nuclei) equipped with two-channel $7 \mathrm{~mm}$ and $4 \mathrm{~mm}$ 
MAS probe heads. The ${ }^{13} \mathrm{C}\left\{{ }^{1} \mathrm{H}\right\}$ NMR spectra with high-power decoupling were referenced to external TMS. They were obtained by direct excitation of ${ }^{13} \mathrm{C}$ nuclei with pulse lengths of $2.5 \mu \mathrm{s}$ $\left(50^{\circ}\right), 1400$ scans, and recycle delays of 5-8 s which afforded full nuclear relaxation. The ${ }^{2} \mathrm{H}$ NMR spectra of static samples were obtained using the Hahn-echo $\left(90^{\circ}-\tau-180^{\circ}-\tau\right)$ pulse sequence $(\tau=50 \mu \mathrm{s})$ with a $90^{\circ}$ pulse length of $5.25 \mu \mathrm{s}$, a recycle delay of $1-3 \mathrm{~s}$, and a number of scans between 300 and 400. The variable temperature NMR experiments were performed with a thermocouple calibrated using the ${ }^{1} \mathrm{H}$ NMR spectra of liquid methanol $\left(\Delta \delta=\delta(\mathrm{OH})-\delta\left(\mathrm{CH}_{3}\right)\right)$ placed into a static MAS NMR rotor. Following a change in the temperature setting, a delay of 15 to 20 minutes was used before the acquisition in order to allow for thermal stabilization.

Simulations of quadrupolar patterns have been performed with a standard Bruker package program of the solid-state NMR spectrometer.

The chemical exchange was approximated with a three-center exchange model. The frequency distance of the outer resonances was taken as $15 \mathrm{kHz}$ (the distance between two main singularities of the pattern with a $\mathrm{C}_{\mathrm{Q}}$ of $20 \mathrm{kHz}$ ). The central resonance belongs to the free benzene molecules. The three-center fitting procedures were performed using the Bruker program Dynamics.

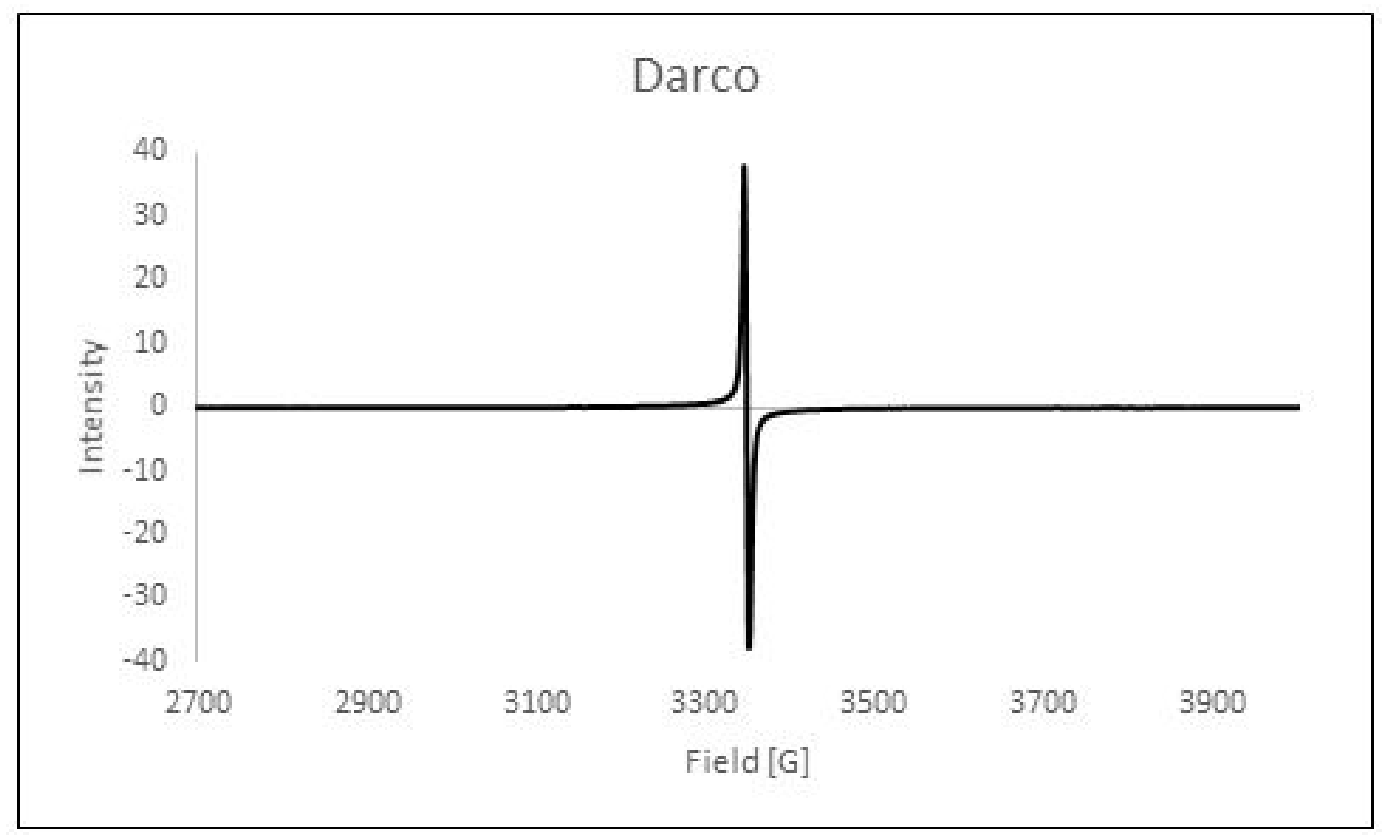

Figure S1. Single-scan ESR spectrum of AC at room temperature. 


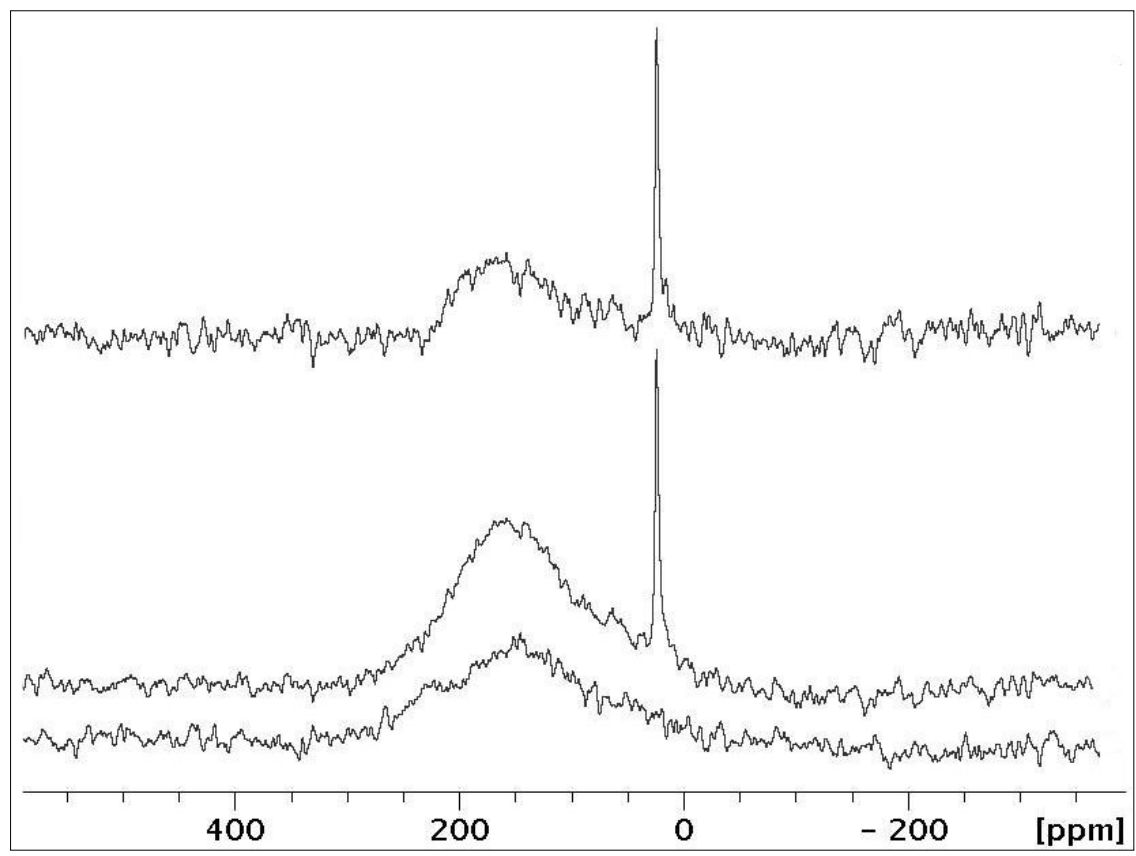

Figure S2. Room-temperature ${ }^{13} \mathrm{C}\left\{{ }^{1} \mathrm{H}\right\}$ NMR spectra recorded without rotation under the same conditions for $\mathbf{A C}-\mathbf{C}_{\mathbf{6}} \mathbf{D}_{\mathbf{1 2}} \mathbf{- 5 5}$ (middle) and the empty rotor (bottom). The difference spectrum (top) shows the broad AC signal and the isotropic benzene resonance. The relative intensities of both signals can be determined from the top spectrum.

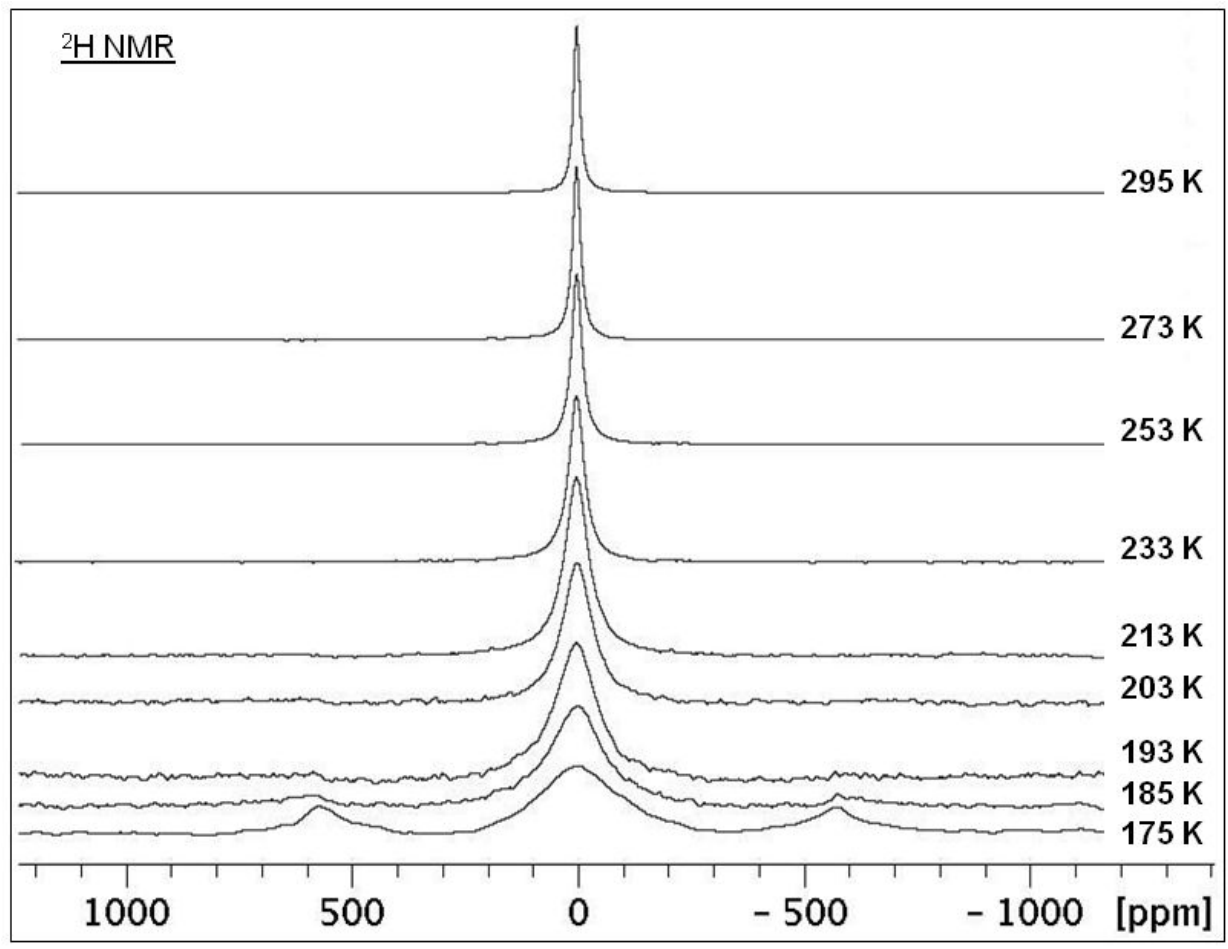

Figure S3. VT ${ }^{2} \mathrm{H}$ NMR spectra obtained for the static sample $\mathbf{A C}-\mathbf{C}_{\mathbf{6}} \mathbf{D}_{\mathbf{6}} \mathbf{- 6 2 0}$ with the Hahnecho $\left(90^{\circ}-\tau-180^{\circ}-\tau\right)$ pulse sequence. 


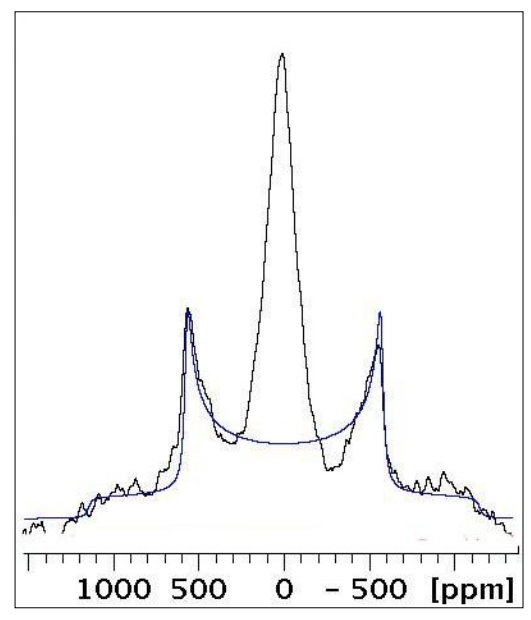

Figure S4. Quadrupolar ${ }^{2} \mathrm{H}$ Pake pattern of stationary benzene molecules observed for sample AC- $\mathbf{C}_{6} \mathbf{D}_{\mathbf{6}}-\mathbf{6 2 0}$ at $175 \mathrm{~K}$, corresponding to a deuterium quadrupolar coupling constant $\left(\mathrm{C}_{\mathrm{Q}}\right)$ of 92 $\pm 3 \mathrm{kHz}$ with an asymmetry parameter $\eta=0.0$.

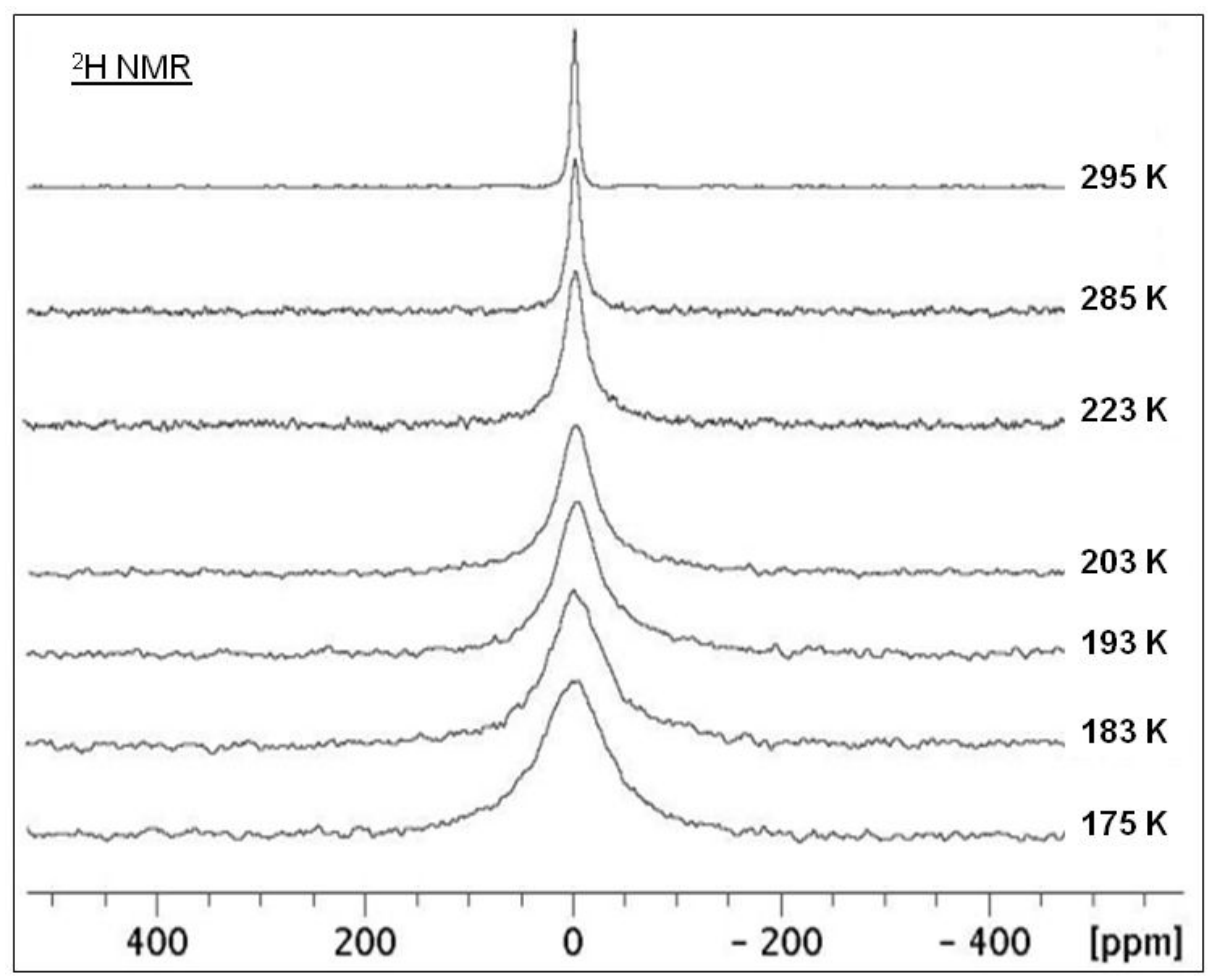

Figure S5. Hahn-echo ${ }^{2} \mathrm{H}$ NMR spectra obtained from a static sample of $\mathbf{A C}-\mathbf{C}_{\mathbf{6}} \mathbf{D}_{\mathbf{1 2}}-\mathbf{5 5}$ at the indicated temperatures. 


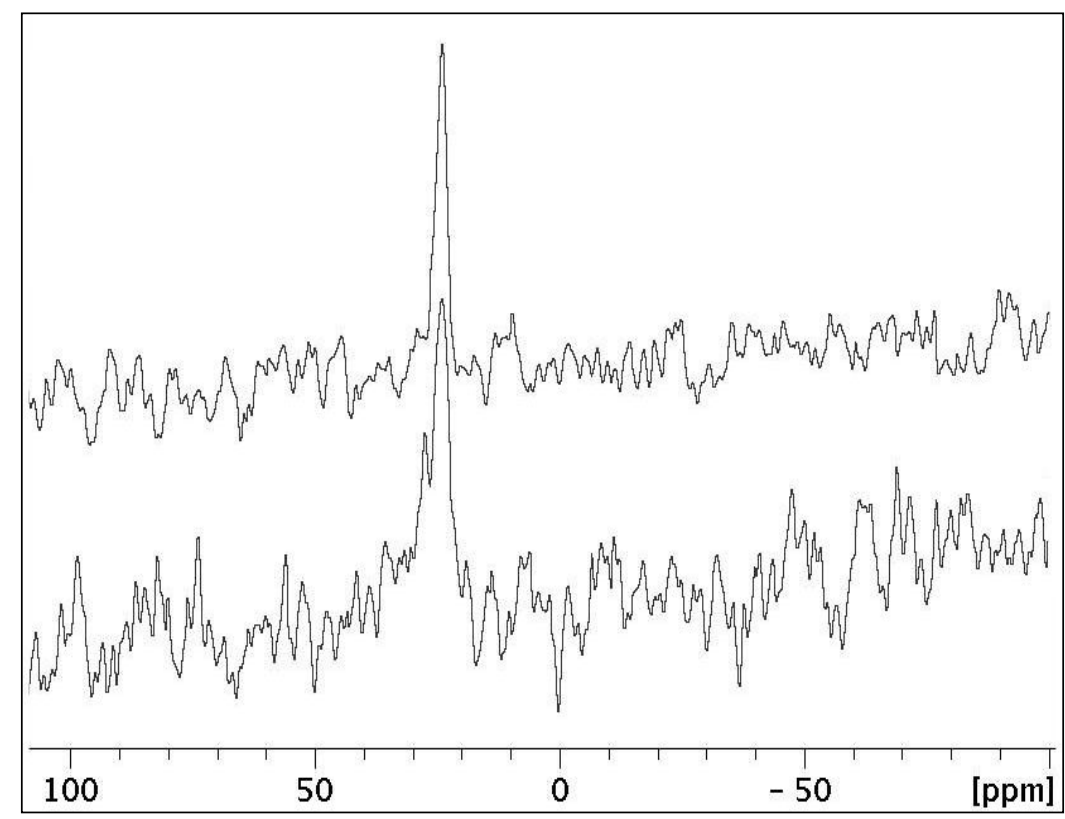

Figure S6. ${ }^{13} \mathrm{C}\left\{{ }^{1} \mathrm{H}\right\}$ NMR spectra of the static sample $\mathbf{A C}-\mathbf{C}_{\mathbf{6}} \mathbf{D}_{\mathbf{1 2}} \mathbf{- 5 5}$ at $295 \mathrm{~K}$ (top) and $175 \mathrm{~K}$ (bottom).

Table S1. The temperature dependence of the halfwidths $(\Delta v)$ for the central components of the ${ }^{2} \mathrm{H}$ signals observed for the static samples $\mathbf{A C}-\mathbf{C}_{\mathbf{6}} \mathbf{D}_{\mathbf{6}}-\mathbf{3 7 0}$, and $\mathbf{A C}-\mathbf{C}_{6} \mathbf{D}_{\mathbf{1 2}} \mathbf{- 5 5}$.

\begin{tabular}{|l|l|l|l|}
\hline \multicolumn{2}{|c|}{ AC-C } & \multicolumn{2}{c|}{ AC- $\mathbf{D}_{\mathbf{6}}-\mathbf{3 7 0} \mathbf{D}_{\mathbf{1 2}} \mathbf{- 5 5}$} \\
\hline$\Delta v(\mathrm{kHz})$ & $\mathrm{T}(\mathrm{K})$ & $\Delta v(\mathrm{kHz})$ & $\mathrm{T}(\mathrm{K})$ \\
\hline 1.2 & 295 & 0.7 & 295 \\
1.5 & 273 & 0.9 & 285 \\
1.8 & 253 & 1.6 & 223 \\
2.3 & 233 & 2.5 & 203 \\
3.9 & 213 & 3.0 & 193 \\
4.6 & 203 & 3.9 & 183 \\
6.2 & 193 & 4.7 & 175 \\
8.3 & 185 & & \\
12.6 & 175 & & \\
\hline
\end{tabular}




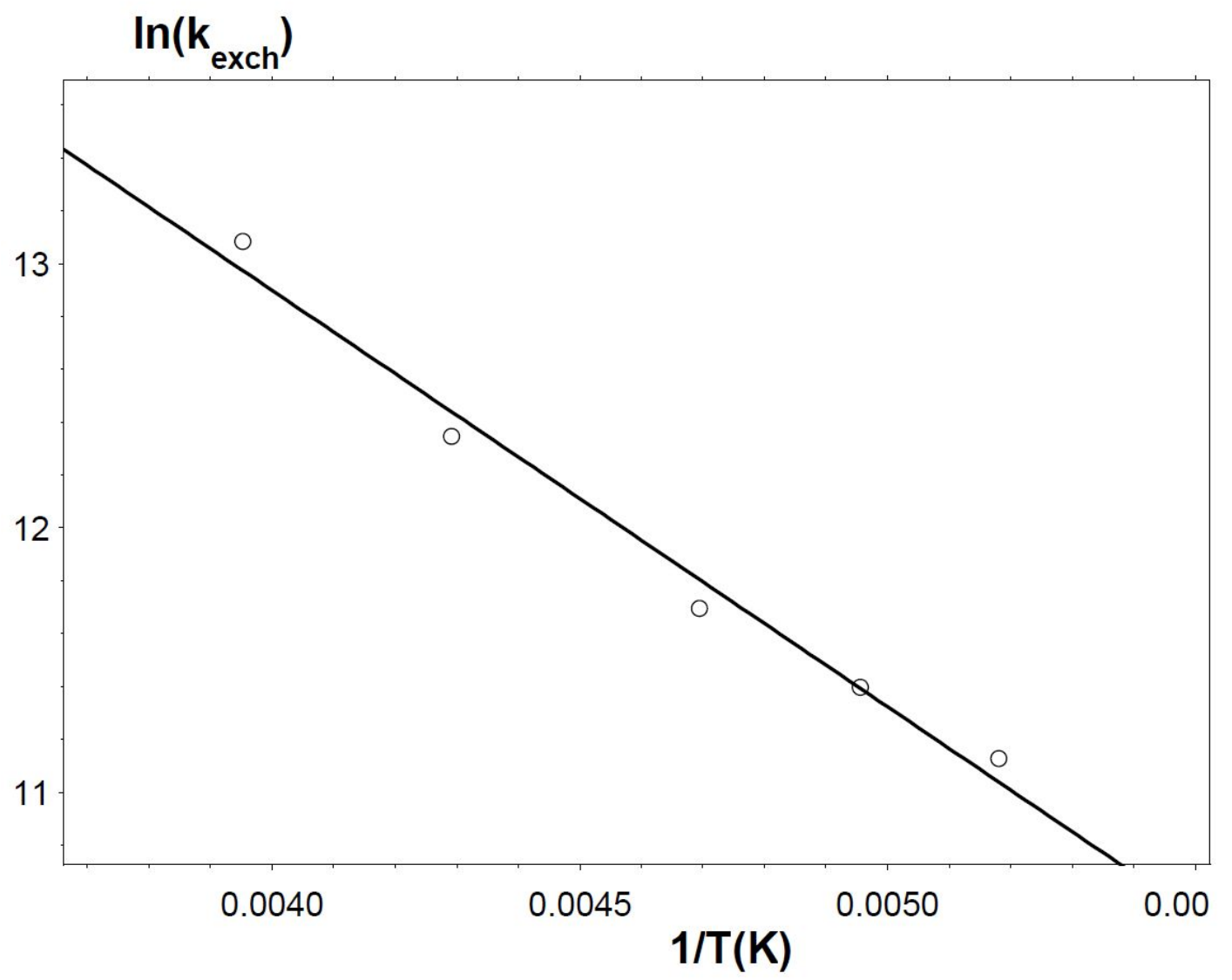

Figure S7. The temperature dependence of the rate constants $\mathrm{k}_{\mathrm{exch}}$ in Table 2, obtained from the central component in the ${ }^{2} \mathrm{H}$ NMR spectra of $\mathbf{A C}-\mathbf{C}_{\mathbf{6}} \mathbf{D}_{\mathbf{6}}-\mathbf{3 7 0}$, presented in the coordinates $\ln \left(\mathrm{k}_{\text {exch }}\right)$ versus $1 / \mathrm{T}$. 